\title{
Effects of Ethanolic Extract of Kiam Wood/Cashew Bark and Commercial Phenolic Compounds Oxidized Under Alkaline Condition on Gel Property of Gelatin from Cuttlefish Skin
}

\author{
Wattan Temdee $^{1}\left(\mathbb{D}\right.$, Soottawat Benjakul ${ }^{1}\left(\mathbb{D}\right.$, Vijay Kumar Reddy Surasani ${ }^{2}{ }^{(}$, \\ Avtar Singh ${ }^{1, *}$
}

\begin{abstract}
${ }^{1}$ Prince of Songkla University, Faculty of Agro-Industry, International Center of Excellence in Seafood Science and Innovation, Hat Yai, Songkhla, 90112, Thailand

${ }^{2}$ Guru Angad Dev Veterinary and Animal Sciences University, College of Fisheries, Ludhiana, Department of Harvest and Post-Harvest Technology, Punjab, 141004, India
\end{abstract}

\section{How to cite}

Temdee, W., Benjakul, S., Surasani, R.K.V., Singh, A., (2021). Effects of Ethanolic Extract of Kiam Wood/Cashew Bark and Commercial Phenolic Compounds Oxidized Under Alkaline Condition On Gel Property of Gelatin from Cuttlefish Skin. Aquatic Food Studies, 1(1), AFS14 https://doi.org/10.4194/AFS14

\section{Article History}

Received 01 June 2021

Accepted 05 July 2021

First Online 09 July 2021

\section{Corresponding Author}

Tel.: +6674286362

E-mail: avtar.s@psu.ac.th

\section{Keywords}

Cuttlefish

Gelatin

Bloom Strength

Phenolic Compounds

Oxidation

\begin{abstract}
The effect of ethanolic extracts of kiam wood (EKW) or cashew bark (ECB) and commercial phenolic compounds oxidized under alkaline condition $(\mathrm{pH}$ 9) on gel properties of gelatin extracted from cuttlefish skin was investigated. All the oxidized compounds increased gel strength (GS) of gelatin, in which the highest value was noticed for gels containing oxidized catechin $(C H-G)$ and gallic acid $(G A-G)(P<0.05)$. Among the ethanolic extracts, the gel added with EKW (EKW-G) had higher GS than that containing ECB gel $(E C B-G)(P<0.05)$. Both extracts yielded gels with similar $G S$ to those added with oxidized ferulic and tannic acids $(P>0.05)$. Lightness and free amino group content of gels were decreased with the addition of oxidized compounds, regardless of their types. Gels added with oxidized compounds showed lower solubility and amino group content as compared to the control, indicating the formation of nondisulphide covalent bonds in the gel matrix. The treated samples showed a gel network with thicker strands and larger voids, compared with the control gel. Overall, oxidized EKW extract had a similar impact on the gel properties of gelatin to the oxidized phenolic compounds, especially catechin and gallic acids.
\end{abstract}

\section{Introduction}

Gelatin is a denatured product of collagen, which has been extracted from the skin, bones, tendon, etc. of various sources including bovine, fish, porcine etc. However, due to health concern, and religious limitations, bovine and porcine gelatins have been prohibited. This brings about the exploitation of fish byproducts such as skin, scales, etc. as a source of gelatin (Sinthusamran et al., 2014). However, fish gelatin has poor bloom strength, compared with mammalian gelatin, which is mainly due to the lower imino acid content (Haug et al., 2004; Karim \& Bhat, 2009). Therefore, various modifications via chemical, enzymatic and physical methods have been employed to enhance the gel properties of gelatin (Huang et al., 2019). Among those methods, modification via phenolic compounds has been widely conducted due to their availability and natural origin (Aewsiri et al., 2009; Anvari \& Chung, 2016; Huang et al., 2019). Moreover, the potential health benefits of phenolics, especially for the prevention of cancer and cardiovascular diseases have been studied extensively (Carocho \& Ferreira, 2013; Mumtaz et al., 2021).

Phenolic compounds are widely present in various parts of plants such as fruits, leaves, barks, woods, etc. Among them, bark or wood contained potentially high phenolic compounds, especially tannic acid. Those 
compounds could be used to enhance the functional properties of gelatin or other proteins via the formation of covalent and non-covalent interactions with proteins (Strauss \& Gibson, 2004; Temdee \& Benjakul, 2014; Temdee \& Benjakul, 2015). In general, diphenol moiety of a phenolic acid or other polyphenol is readily oxidized to an ortho-quinone with the help of enzymes, alkaline condition, etc. (Balange \& Benjakul, 2009; Balange \& Benjakul, 2009; Temdee \& Benjakul, 2014). Those quinones can covalently bind to protein amino groups via $\mathrm{C}-\mathrm{N}$ or $\mathrm{C}-\mathrm{S}$ bonds, which can increase the interactions between protein chains, resulting in higher connection and increased gel strength (Strauss \& Gibson, 2004; Zhao \& Sun, 2017). Balange and Benjakul (2009) reported an increased gel strength of surimi from mackerel with the addition of oxidized tannic acid. Temdee and Benjakul (2014) used laccase to oxidize the natural or commercial phenolic compounds, which were used for improving the gel properties of gelatin extracted from cuttlefish. In the current study, an alkaline condition was used to oxidize the phenolic compounds as a cheap alternative method. So far, no report has been available on the use of oxidized phenolic compounds from wood/bark prepared using alkaline conditions for gel improvement. The information gained would be of benefit in using the natural extract containing phenolic compounds for strengthening the gelatin gel, in which functional properties can be maximized and full benefit can be gained.

\section{Materials and Methods}

\section{Cuttlefish Skin}

The cuttlefish (Sepia pharaonis) skin was brought from a dock in Songkhla and transferred to the International Center of Excellence in Seafood Science and Innovation (ICE-SSI), Prince of Songkla University within $1 \mathrm{~h}$ under iced condition. Thereafter, skin was cleaned with tap-water and cut into $1 \times 1 \mathrm{~cm}$ pieces and stored in polyethylene bags at $-20^{\circ} \mathrm{C}$ and used within two months.

\section{Preparation of Oxidized Phenolic Compounds}

Firstly, the ethanolic extracts of kiam (Cotylelobium lanceotatum craih) wood (EKW) and cashew (Anacardium occidentale) bark (ECB) were prepared as per the method given by Temdee and Benjakul (2014). The oxidation of EKW and ECB was carried out using the alkaline method, in which extracts $(0.05 \mathrm{~g})$ were dissolved in $5 \mathrm{ml}$ of ethanol and $90 \mathrm{ml}$ of distilled water. The solutions were adjusted to $\mathrm{pH} 9$ using $6 \mathrm{~N} \mathrm{NaOH}$ or $6 \mathrm{~N} \mathrm{HCl}$. The prepared solutions were placed in a temperature-controlled water bath $\left(40^{\circ} \mathrm{C}\right)$ and subjected to oxygenation for $30 \mathrm{~min}$ by bubbling the solution with oxygen. After being oxygenated for 30 min, the solution was then neutralized by using $2 \mathrm{M} \mathrm{HCl}$ and the final solution was adjusted to $100 \mathrm{ml}$ using the distilled water and was referred to as 'oxidized phenolic compound'. Similarly, commercially available phenolic acids including catechin, ferulic acid, tannic acid and gallic acid were oxidized under the aforementioned condition. The total phenolic content of EKW and ECB were 438.76 and $253.57 \mathrm{~g} / \mathrm{kg}$, respectively as determined using Folin-Ciocalteu reagent (Buamard \& Benjakul, 2017).

\section{Extraction of Gelatin}

Firstly, the frozen skin was thawed at $4^{\circ} \mathrm{C}$ followed by the stirring (IKA Laboratory equipment, Staufen, Germany) with $0.4 \mathrm{M} \mathrm{NaOH}$ and $0.75 \% \mathrm{H}_{2} \mathrm{O}_{2}$ at a sample/solution ratio of $1: 10(\mathrm{w} / \mathrm{v})$ for $12 \mathrm{~h}$ at $4{ }^{\circ} \mathrm{C}$. During the process, the solution was changed three times at every $3 \mathrm{~h}$. The pre-treated skin was soaked in $10 \% \mathrm{H}_{2} \mathrm{O}_{2}(1: 10 ; \mathrm{w} / \mathrm{v})$ at $4^{\circ} \mathrm{C}$ for $48 \mathrm{~h}$ with continuous stirring. All samples were washed with tap water until the neutral $\mathrm{pH}$ of washed water. Then skins were added with five volumes of warm water to extract gelatin for $18 \mathrm{~h}$ at $50^{\circ} \mathrm{C}$. The solution was centrifuged at $10,000 \times \mathrm{g}$ for 20 min using a centrifuge (Beckman Coulter Inc., Newton, CT, USA) at $25 \circ$ C. The obtained supernatant was collected and freeze-dried (Coolsafe 55, ScanLafA/S, Lynge, Denmark). To confirm the gelatin identity, protein structure and functional groups, the gelatin powder was subjected to Fourier transform infrared (FTIR) analysis.

\section{Preparation of Gelatin Gel}

Gelatin gels $(6.67 \% ; \mathrm{w} / \mathrm{v})$ containing $2 \%(\mathrm{w} / \mathrm{w})$ of oxidized compounds were prepared following the method of Sinthusamran et al. (2014). The gelatin gels were stored at $4^{\circ} \mathrm{C}$ for $16-18 \mathrm{~h}$ before analysis. The gelatin gel added with oxidized ECB, EKW, catechin $(\mathrm{CH})$, ferulic acid (FA), tannic acid (TA), and gallic acid (GA) were denoted as ECB-G, EKW-G, CH-G, FA-G, TA-G and $\mathrm{GA}-\mathrm{G}$, respectively.

\section{Analyses}

\section{Gel Strength (GS)}

GS of the gelatin gels $\left(10^{\circ} \mathrm{C}\right)$ without and with various oxidized compounds was determined using a texture analyzer (Model TA-XT2, Stable Micro System, Surrey, UK) according to the procedure given by Sinthusamran et al. (2014).

\section{Color}

The $L^{*}$ (lightness), $a^{*}$ (redness/greenness), and $b^{*}$ (yellowness/blueness) and total color difference $\left(\Delta E^{*}\right)$ of gels were determined using a colorimeter (ColourFlex, HunterLab Reston, VA) following the method of Temdee and Benjakul (2015). 


\section{Free Amino Group (FAG) Contents}

FAG content was determined using the trinitrobenzene sulfonic acid method according to the procedure given by Nagarajan et al. (2012) The optical density was determined at $420 \mathrm{~nm}$ and FAG contents were recorded in terms of L-leucine.

\section{Solubility}

Proteins solubility of gelatin gel in various solvents including $20 \mathrm{mM}$ Tris- $\mathrm{HCl}(\mathrm{pH}$ 8) containing 1\% SDS (S1) or $1 \% \mathrm{SDS}+8 \mathrm{M}$ urea (S2) or $1 \% \mathrm{SDS}+2 \% \beta$ mercaptoethanol $+8 \mathrm{M}$ urea (S3) determined by the method of Benjakul et al. (2009).

\section{Scanning Electron Microscopic (SEM) Images}

The microstructures of gelatin gels added without and with various oxidize extracts or phenolic compounds were observed using SEM by the method of Benjakul et al. (2009). Gel samples with a thickness of 2$3 \mathrm{~mm}$ cut using a sharp razor were fixed with $2.5 \%(\mathrm{v} / \mathrm{v})$ glutaraldehyde in $0.2 \mathrm{M}$ phosphate buffer ( $\mathrm{pH} 7.2)$. The samples were then rinsed with distilled water before being dehydrated in ethanol with serial concentrations of $50 \%, 70 \%, 80 \%, 90 \%$ and $100 \%(\mathrm{v} / \mathrm{v})$. Dried samples were mounted on a bronze stub and sputter-coated with gold (Sputter coater SPI-Module, West Chester, PA, USA). The specimens were observed with a scanning electron microscope (JEOL JSM-5800 LV, Tokyo, Japan) at an acceleration voltage of $10 \mathrm{kV}$.

\section{Statistical Analysis}

A completely randomized design (CRD) was employed for the whole studies. All the experiments were performed in triplicate and data were subjected to analysis of variance and differences between means were evaluated by Duncan's multiple range test (Steel and Torrie, 1980) using the SPSS statistical program (Version 20.0) (SPSS Inc., Chicago, IL).

\section{Results and Discussion}

\section{FTIR Spectrum of Gelatin Powder}

FTIR spectrum of gelatin from the skin of cuttlefish extracted at $50^{\circ} \mathrm{C}$ for $18 \mathrm{~h}$ is shown in Figure 1. In general, protein contains five major bands namely amide $A, B, I, I$, and III appearing at wavenumbers of 3304-3315, 2922-2940, 1644-1653, 1541-1548 cm and 1237-1239 cm $\mathrm{cm}^{-1}$ (Aewsiri et al., 2009; Singh et al., 2020; Sinthusamran et al., 2014). In cuttlefish gelatin, amide I representing $\mathrm{CO}$ stretching/hydrogen bonding coupled with COO- was noticed at wavenumber 1644 $\mathrm{cm}^{-1}$. Amide II and III bands were observed at wavenumbers of 1542 and $1234 \mathrm{~cm}^{-1}$, respectively. The former band is characteristic of $\mathrm{NH}$ bending, coupled with $\mathrm{CN}$ stretching and the latter shows $\mathrm{NH}$ bending (Singh et al., 2020). The amide A (NH-stretching, coupled with hydrogen bonding) and amide $B(\mathrm{CH}$ stretching vibrations of $-\mathrm{CH}_{2}$ group) were noticed at wavenumbers of 3294 and $2919 \mathrm{~cm}^{-1}$, respectively (Nagarajan et al., 2012; Sinthusamran et al., 2014). Wavenumbers of those major five amide bands could be influenced by the extraction conditions, species or source of gelatin. Nagarajan et al. (2012) observed variations in the wavenumbers when gelatin from squid skin was extracted using various temperatures. Different pretreatments or extraction conditions led to the differences in degradation, deamination, etc. between gelatins. Overall, cuttlefish skin gelatin structure was confirmed by the FTIR spectrum, which was associated with the presence of characteristics amide bands of gelatin.

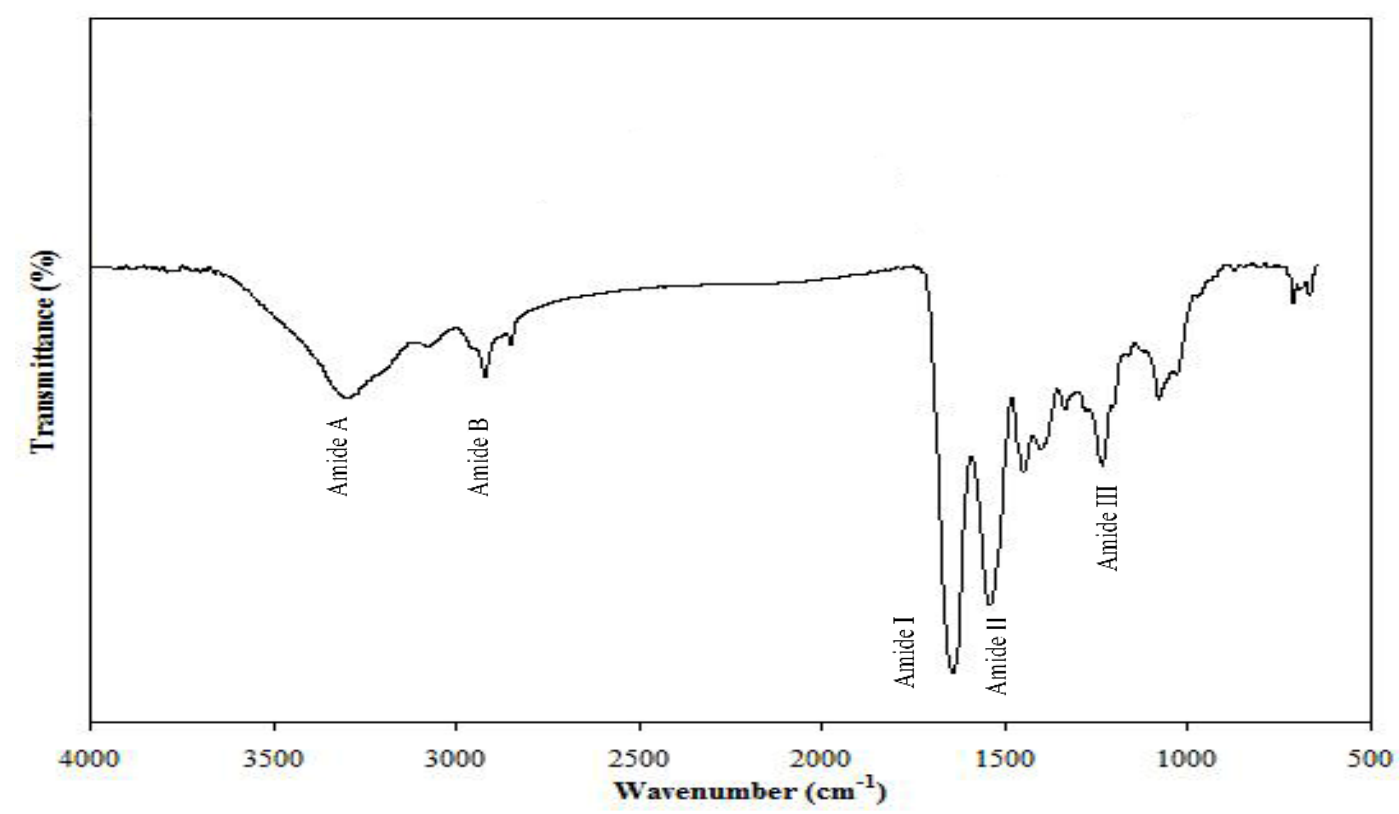

Figure 1. FTIR spectrum of gelatin powder extracted from cuttlefish skin. 


\section{Gel Strength (GS)}

GS of samples added without and with oxidized extracts or phenolic compounds under alkaline conditions is depicted in Figure 2. The control sample had the lower GS than the treated samples $(P<0.05)$. The ECB-G had the lowest GS as compared to EKW-G and other treated samples $(P<0.05)$. This was more likely due to the lower total phenolic content as well as tannin content (data not shown) in ECB than the EKW extract (Temdee \& Benjakul, 2014), which resulted in the lower quinone content formed during oxygenation under alkaline condition. In general, quinone is electrophile, which could react with a nucleophilic amino group of proteins (Buamard \& Benjakul, 2017; Temdee \& Benjakul, 2014). Moreover, they can form dimers between amino or sulfhydryl side chains of polypeptides along with the formation of $\mathrm{C}-\mathrm{N}$ or $\mathrm{C}-\mathrm{S}$ bonds with the phenolic ring (Temdee \& Benjakul, 2014; Vate \& Benjakul, 2016). Therefore, the lower protein crosslinking was obtained in the gel samples added with oxidized ECB. EKW-G sample had a similar GS to TA-G and $F A-G$ samples $(P>0.05)$. Nevertheless, it had lower $\mathrm{GS}$, compared to $\mathrm{CH}-\mathrm{G}$ and $\mathrm{GA}-\mathrm{H}$ sample $(\mathrm{P}<0.05)$. For $\mathrm{CH}-\mathrm{G}$ and $\mathrm{GA}-\mathrm{H}$ samples, the highest $\mathrm{GS}$ was obtained as compared to the remaining samples $(P<0.05)$; however, no difference was noticed between both samples $(P>0.05)$. This was more likely due to their smaller size, which might disperse uniformly and could interact with amino groups of gelatin more effectively (Temdee \& Benjakul, 2014). Moreover, catechin has a higher number of hydroxyl groups than others, which made its easy interactions with proteins. Thus, the molecular properties of commercial phenolic compounds and the composition of the extracts influenced the GS of gelatin gels. Although oxidized EKW resulted in lower GS than oxidized catechin and gallic acids, it showed the same ability to improve gel strength with oxidized ferulic and tannic acids when added into the gelatin. Therefore, those oxidized natural extracts could be a possible alternative for improving the gel quality of gelatin or other proteins.

Color

The color of the gels containing different oxidized extracts or phenolic compounds is shown in Table 1. All the gels added with oxidized compounds (38.87-62.72) had a lower $L^{*}$-value as compared to the control gel (64.22) $(P<0.05)$. The lowest $L^{*}$-value was noticeable for GA-G $(P<0.05)$, whereas the highest value was noted for the FA-G sample $(P<0.05)$. For gels added with oxidized ethanolic extracts, EKW-G had a higher lightness than the ECB-G $(P<0.05)$. The redness and yellowness of the gel incorporated with all compounds increased, as indicated by the increase in $a^{*}$-value and $b^{*}$-value, respectively, compared to the control gel. The ECB-G had the highest $a^{*}$-value as compared to the remaining samples, while the lowest value was found for the control and FA-G samples $(\mathrm{P}<0.05)$. For the $b^{*}$-value, the $\mathrm{CH}-\mathrm{G}$ sample had the highest value as compared to the other samples. Among the treated samples, the FA-G sample had the lowest $b^{*}$-values followed by the ECB-G sample $(P<0.05)$. Similarly, Cao et al. (2007) and Theerawitayaart et al. (2021) reported changes in the color of gelatin films when incorporated with various oxidized phenolic compounds. The increased yellowness/redness and lower whiteness of gels might be caused by the non-enzymatic browning of gelatin (Theerawitayaart et al., 2021). For a total difference in color value ( $\Delta E^{*}$-value), $\mathrm{FA}-\mathrm{G}$ had the lowest value $(\mathrm{P}<0.05)$. On the other hand, the highest $\Delta E^{*}$-value was noticed for $\mathrm{CH}-\mathrm{G}$ followed by the $\mathrm{GA}-\mathrm{G}$ sample $(\mathrm{P}<0.05)$. The low $\Delta E^{*}$-values were in line with the high lightness value. Therefore, the addition of oxidized extracts or phenolic compounds as gel enhancers might lead to the discoloration of the resulting gel, depending upon the type of compounds.

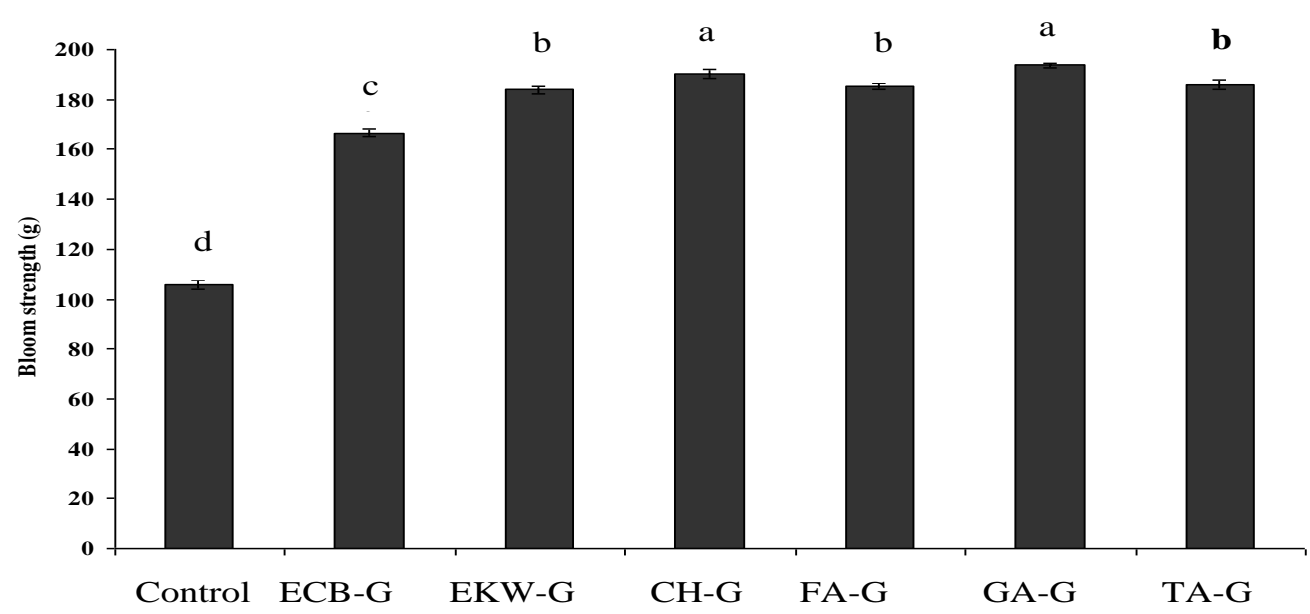

Figure 2. Gel strength of gelatin gel from cuttlefish skin incorporated with different oxidized extracts or commercial phenolic compounds. Bars represent the standard deviation $(n=3)$. Different letters on the bars denote the significant differences $(p<0.05)$. Control: without additives; ECB-G, EKW-G, CH-G, FA-G, TA-G, and GA-G: gelatin gel containing 2\% oxidized ECB, EKW, catechin, ferulic acid, tannic acid, and gallic acid, respectively. 


\section{Free Amino Group (FAG) Contents}

The highest FAG contents were noticed for control gel $(P<0.05)$ followed by ECB-G, EKW-G, FA-G, and TA-G samples, respectively (Figure 3 ), which showed similar FAG contents $(P>0.05)$. The lowest $F A G$ content was found for $\mathrm{GA}-\mathrm{G}$ and $\mathrm{CH}-\mathrm{G}$ samples $(\mathrm{P}<0.05)$. In general, decreasing FAG content indicated higher interactions between oxidized compounds and protein side chains, which resulted in higher cross-linking (Temdee \& Benjakul, 2014; Theerawitayaart et al., 2021). Free amino groups might interact with quinones formed during the oxygenation under alkaline conditions (Temdee \& Benjakul, 2014; Theerawitayaart et al., 2021). Moreover, at alkaline $\mathrm{pH}$, hydroxyl groups could be oxidized to form a free hydroxyl radical, which might react with a benzene ring, causing oxidation followed by polymerization (Rawel et al., 2000). The decreasing FAG content was in line with the increased GS for gels added with oxidized gallic acid and catechin (Figure 2).

\section{Solubility}

Protein solubilities of gelatin gels incorporated without and with oxygenated extracts or phenolic compounds in various solvents such as $20 \mathrm{mM}$ Tris- $\mathrm{HCl}$ (pH 8) containing $1 \%$ SDS (S1) or $1 \%$ SDS $+8 \mathrm{M}$ urea(S2) or $1 \% \mathrm{SDS}+2 \% \beta-\mathrm{ME}+8 \mathrm{M}$ urea (S3) are shown in Table 2. Samples namely, GA-G and $\mathrm{CH}-\mathrm{G}$, showed the lowest solubility, regardless of types of solvents used $(P<0.05)$. For S1, the highest solubility was noticed for the control, $E C B-G$ and EKW-G samples $(P<0.05)$. For the remaining samples, no difference in solubility was noticed $(P>0.05)$. The lower solubility of the samples was in agreement with the higher GS of gel samples (Figure 1). $\mathrm{S} 1$ has been used to destroy weak bonds such as $\mathrm{H}$-bond, etc., while S2 containing SDS and urea could break down hydrophobic interactions (Temdee \& Benjakul, 2014). S3 containing SDS in combination with urea or $\beta-\mathrm{ME}$ has been known to destroy $\mathrm{H}$-bond, hydrophobic interaction and disulphide bond, respectively (Temdee \& Benjakul, 2014). When compared among the different solvents used, S3 yielded the higher solubility than S2 followed by $S 1$, regardless of samples $(P<0.05)$. Hence, the decrease in solubility in S3 suggested the higher involvement of non-disulphide covalent bonds in the gel samples. Non-significantly lowest solubility of $\mathrm{CH}-\mathrm{G}$ and GA-G samples was in accordance with the lowest FAG contents in both gel samples. The result reconfirmed the formation of quinones, which could act as the potential cross-linker and produced a strong gel matrix.

\section{Scanning Electron Microscopy (SEM)}

The microstructures of the gels incorporated without and with oxidized extracts and phenolic compounds are illustrated in Figure 4 A-G. Generally, the gelatin gel strength is determined by the ordered arrangement and association of protein chains in the gel matrix. Gelatin gels are sponge-like or coral-like containing pores of different sizes and uniformity (Sinthusamran et al., 2014). The control gel had a uniform network with a thin strand as compared to those treated with oxidized extracts or phenolic

Table 1. Color of gelatin gel from cuttlefish skin incorporated with different oxidized extracts or commercial phenolic compounds.

\begin{tabular}{|c|c|c|c|c|}
\hline \multirow{2}{*}{$\begin{array}{l}\text { Oxidized extracts/ } \\
\text { compounds }\end{array}$} & \multicolumn{4}{|c|}{ Color } \\
\hline & $L^{*}$ & $a^{*}$ & $b^{*}$ & $\Delta E^{*}$ \\
\hline Control & $64.22 \pm 0.73^{a}$ & $-6.39 \pm 0.17^{f}$ & $9.18 \pm 0.68^{f}$ & - \\
\hline ECB-G & $43.33 \pm 0.69^{e}$ & $9.65 \pm 0.54^{a}$ & $13.79 \pm 0.70^{d}$ & $26.73 \pm 0.23^{c}$ \\
\hline EKW-G & $49.73 \pm 0.66^{d}$ & $3.89 \pm 0.44^{d}$ & $20.08 \pm 1.07^{c}$ & $20.84 \pm 0.12^{d}$ \\
\hline $\mathrm{CH}-\mathrm{G}$ & $49.83 \pm 0.67^{d}$ & $5.82 \pm 0.53^{c}$ & $37.11 \pm 0.91^{\mathrm{a}}$ & $33.70 \pm 0.36^{a}$ \\
\hline FA-G & $62.72 \pm 0.70^{b}$ & $-6.10 \pm 0.12^{f}$ & $11.29 \pm 0.93^{\mathrm{e}}$ & $2.60 \pm 0.01^{f}$ \\
\hline GA-G & $38.87 \pm 0.70^{f}$ & $7.26 \pm 0.76^{b}$ & $21.21 \pm 0.77^{b}$ & $31.20 \pm 0.32^{b}$ \\
\hline TA-G & $50.74 \pm 0.23^{c}$ & $0.29 \pm 0.34^{\mathrm{e}}$ & $21.70 \pm 0.87^{b}$ & $19.57 \pm 0.32^{e}$ \\
\hline
\end{tabular}

Mean $\pm S D$ from $(n=3)$. Different superscripts in the same column indicate significant differences $(P<0.05)$.

Table 2. Protein solubility of gelatin gel from cuttlefish skin incorporated with different oxidized extracts or commercial phenolic compounds in various solvents.

\begin{tabular}{|c|c|c|c|}
\hline \multirow{2}{*}{ Oxidized extract/compounds } & \multicolumn{3}{|c|}{ Solubility (\%) } \\
\hline & S1 & $\mathrm{S} 2$ & S3 \\
\hline Control & $69.02 \pm 0.98^{a}$ & $94.15 \pm 1.21^{a}$ & $98.15 \pm 1.72^{a}$ \\
\hline ECB-G & $68.63 \pm 0.78^{\mathrm{a}}$ & $93.82 \pm 0.40^{\mathrm{a}}$ & $97.99 \pm 0.54^{a}$ \\
\hline EKW-G & $68.55 \pm 2.76^{a}$ & $92.80 \pm 0.46^{b c}$ & $96.61 \pm 1.12^{\mathrm{bc}}$ \\
\hline $\mathrm{CH}-\mathrm{G}$ & $63.90 \pm 0.49 c$ & $89.92 \pm 0.25^{c}$ & $93.32 \pm 2.06^{c}$ \\
\hline FA-G & $65.22 \pm 1.61^{b c}$ & $92.66 \pm 2.53^{b c}$ & $96.42 \pm 0.39 b c$ \\
\hline GA-G & $63.14 \pm 1.74^{c}$ & $90.10 \pm 0.45^{c}$ & $93.71 \pm 1.27 c$ \\
\hline TA-G & $65.39 \pm 3.14^{b c}$ & $91.75 \pm 1.22^{\mathrm{bc}}$ & $96.21 \pm 1.59^{b c}$ \\
\hline
\end{tabular}

Mean $\pm S D(n=3)$. Different superscripts in the same column indicate significant differences ( $P<0.05)$. S1: $20 \mathrm{mM}$ Tris, $\mathrm{pH} 8.0$ containing $1 \%$ ( $w / v)$ SDS; S2: $20 \mathrm{mM}$ Tris, $\mathrm{pH} 8.0$ containing $1 \%(\mathrm{w} / \mathrm{v})$ SDS and $8 \mathrm{M}$ urea; S3: $20 \mathrm{mM}$ Tris, $\mathrm{pH} 8.0$ containing $1 \%(\mathrm{w} / \mathrm{v}) \mathrm{SDS}, 8 \mathrm{M}$ urea, and $2 \%(\mathrm{v} / \mathrm{v})$ B-mercaptoethanol. 


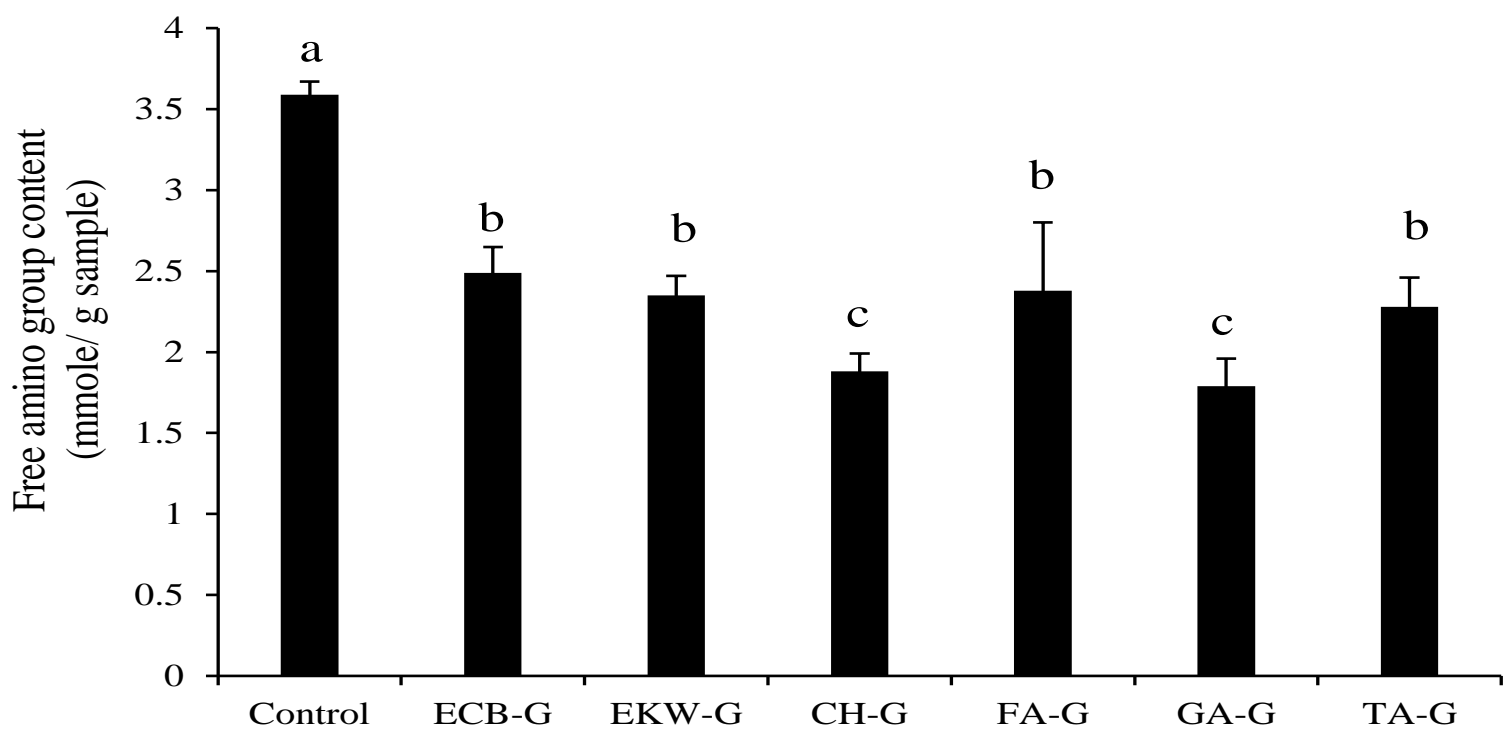

Figure 3. Free amino group contents of gelatin gel from cuttlefish skin incorporated with different oxidized extracts or commercial phenolic compounds. Bars represent the standard deviation $(n=3)$. Different letters on the bars denote the significant differences $(p<0.05)$. For caption see Figure 2.

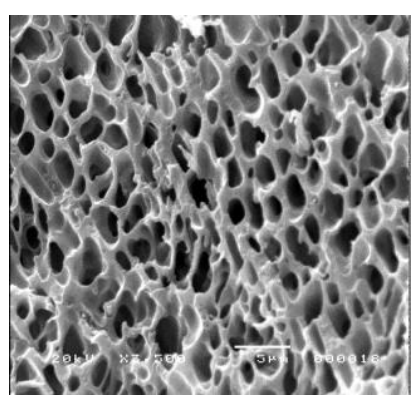

A

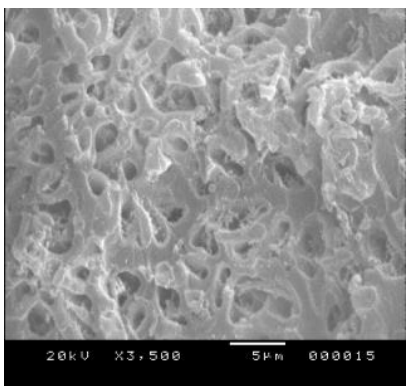

D

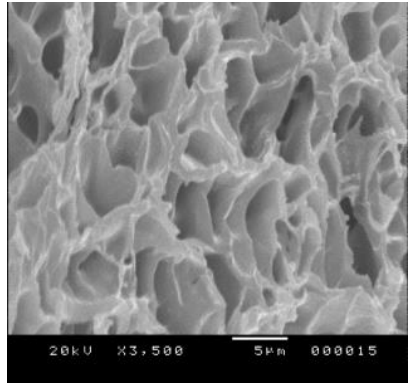

G

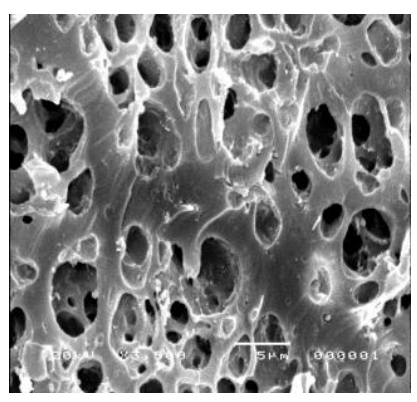

B

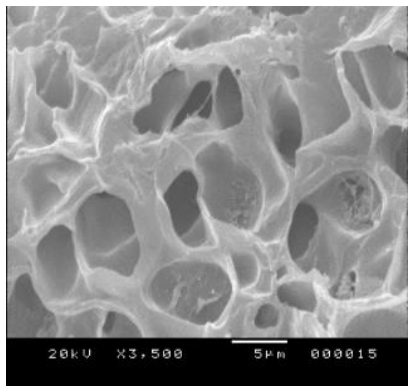

$\mathbf{E}$

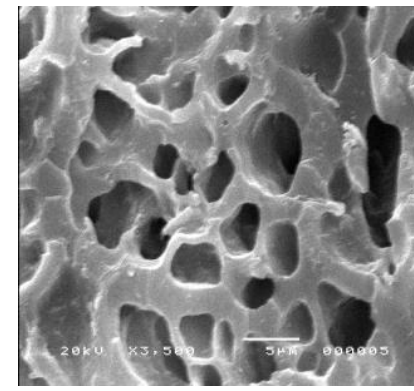

C

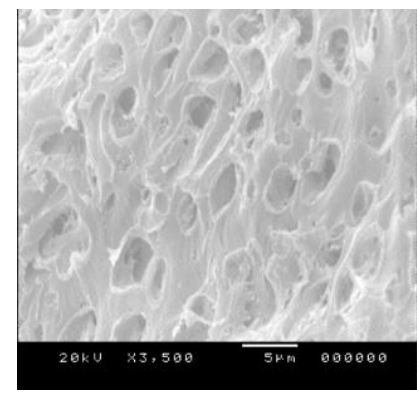

$\mathbf{F}$

Figure 4. Electron microscopic images gelatin gel from cuttlefish skin incorporated with different oxidized extracts or commercial phenolic compounds. Control (A), ECB-G (B), EKW-G (C), CH-G (D), FA-G (E), TA-G (F), and GA-G (G). Magnification 3000x. For caption see Figure 2. 
compounds (Figure $4 \mathrm{~A}$ ). When the oxidized compounds were incorporated into the gels, larger holes with thick strands were appeared (Figure $4 \mathrm{~B}-\mathrm{G}$ ). For $\mathrm{GA}-\mathrm{G}$ and $\mathrm{CH}$ $G$ samples having the highest $B G S$, gel matrix had smaller voids as compared to the other treated samples (Figure $4 \mathrm{D}$ and $\mathrm{F}$, respectively). For the oxidized ethanolic extracts, no major difference in the microstructure was noticed for both the samples (Figure $4 \mathrm{~B}$ and $\mathrm{C}$, respectively). Among the commercial oxidized phenolic compounds, the $\mathrm{CH}-\mathrm{G}$ and $\mathrm{GA}-\mathrm{G}$ samples showed more compact structure with smaller voids and thicker strands of proteins compared to the control. Overall, oxidized extracts or phenolic compounds could function as the gelatin cross-linker and induced the formation of thick strands, which resulted in augmented gel strength.

\section{Conclusion}

Ethanolic extract from kiam wood, cashew bark and commercial phenolic compounds were able to cross-link gelatin after being oxidized by oxygenation under alkaline conditions. All the oxidized extracts/phenolic compounds improved the gel strength of gelatin from cuttlefish skin as compared to the control. However, those oxidized extracts/phenolic compounds reduced the lightness of all the gels. The gel strengthening effects were also supported by the lower free amino groups and gel solubility. Overall, when compared with ECB, EKW could increase the gel strength of gelatin from cuttlefish skin to a higher extent. Oxidized catechin and gallic acids could increase gel strength more efficiently than other oxidized phenolic compounds. Thus, oxidized compounds could be used as gel enhancers, but efficacy was dependent on the type of compounds.

\section{Ethical Statement}

This article does not contain any studies involving animals performed by any of the authors.

\section{Funding Information}

This study was funded by the Prince of Songkla University (PSU), Hat Yai, Thailand (Grant no. AGR6402088N)

\section{Author Contribution}

Conceptualization, A.S. and S.B.; methodology, W.T. and A.S.; software, A.S.; validation, A.S., and S.B..; formal analysis, A.S. and W.T.; investigation, A.S.; resources, S.B.; data curation, A.S. and S.B.; writingoriginal draft preparation, A.S.; writing-review and editing, S.B. and V. K. R. S.; visualization, A.S and V. K. R. S.; supervision, A.S. and S.B.; project administration, S.B.; funding acquisition, S.B. All authors have read and agreed to the published version of the manuscript.

\section{Conflict of Interest}

The author(s) declare that they have no known competing financial or non-financial, professional, or personal conflicts that could have appeared to influence the work reported in this paper.

\section{References}

Aewsiri, T., Benjakul, S., Visessanguan, W., Eun, J.-B., Wierenga, P.A., \& Gruppen, H. (2009). Antioxidative activity and emulsifying properties of cuttlefish skin gelatin modified by oxidised phenolic compounds. Food Chemistry, 117, 160-168.

Anvari, M., \& Chung, D. (2016). Dynamic rheological and structural characterization of fish gelatin - Gum arabic coacervate gels cross-linked by tannic acid. Food Hydrocolloids, 60, 516-524.

Balange, A., \& Benjakul, S. (2009). Enhancement of gel strength of bigeye snapper (Priacanthus tayenus) surimi using oxidised phenolic compounds. Food Chemistry, 113(1), 61-70.

Balange, A.K., \& Benjakul, S. (2009). Effect of oxidised tannic acid on the gel properties of mackerel (Rastrelliger kanagurta) mince and surimi prepared by different washing processes. Food Hydrocolloids, 23, 1693-1701.

Benjakul, S., Oungbho, K., Visessanguan, W., Thiansilakul, Y., \& Roytrakul, S. (2009). Characteristics of gelatin from the skins of bigeye snapper, Priacanthus tayenus and Priacanthus macracanthus. Food Chemistry, 116, 445451.

Buamard, N., \& Benjakul, S. (2017). Cross-linking activity of ethanolic coconut husk extract toward sardine (Sardinella albella) muscle proteins. Journal of Food Biochemistry, 41, e12283.

Cao, N., Fu, Y., \& He, J. (2007). Mechanical properties of gelatin films cross-linked, respectively, by ferulic acid and tannin acid. Food Hydrocolloids, 21, 575-584.

Carocho, M., \& CFR Ferreira, I. (2013). The role of phenolic compounds in the fight against cancer-a review. AntiCancer Agents in Medicinal Chemistry (Formerly Current Medicinal Chemistry-Anti-Cancer Agents), 13, 12361258.

Haug, I.J., Draget, K.I., \& Smidsrød, O. (2004). Physical and rheological properties of fish gelatin compared to mammalian gelatin. Food Hydrocolloids, 18, 203-213.

Huang, T., Tu, Z.-C., Shangguan, X., Sha, X., Wang, H., Zhang, L., \& Bansal, N. (2019). Fish gelatin modifications: A comprehensive review. Trends in Food Science and Technology, 86, 260-269.

Karim, A.A., \& Bhat, R. (2009). Fish gelatin: properties, challenges, and prospects as an alternative to mammalian gelatins. Food Hydrocolloids, 23, 563-576.

Laemmli, U.K. (1970). Cleavage of structural proteins during the assembly of the head of bacteriophage T4. Nature, 227, 680-685.

Mumtaz, M.Z., Kausar, F., Hassan, M., Javaid, S., \& Malik, A. (2021). Anticancer activities of phenolic compounds from Moringa oleifera leaves: in vitro and in silico mechanistic study. Beni-Suef University Journal of Basic and Applied Sciences, 10, 1-11.

Nagarajan, M., Benjakul, S., Prodpran, T., Songtipya, P., \& Kishimura, H. (2012). Characteristics and functional properties of gelatin from splendid squid (Loligo formosana) skin as affected by extraction temperatures. 
Food Hydrocolloids, 29, 389-397.

Rawel, H.M., Kroll, J., \& Riese, B. (2000). Reactions of chlorogenic acid with lysozyme: physicochemical characterization and proteolytic digestion of the derivatives. Journal of Food Science, 65, 1091-1098.

Singh, A., Idowu, A.T., Benjakul, S., Kishimura, H., Aluko, R.E., \& Kumagai, Y. (2020). Debittering of salmon (Salmo salar) frame protein hydrolysate using 2-butanol in combination with $\beta$-cyclodextrin: Impact on some physicochemical characteristics and antioxidant activities. Food Chemistry, 321, 126686.

Sinthusamran, S., Benjakul, S., \& Kishimura, H. (2014). Characteristics and gel properties of gelatin from skin of seabass (Lates calcarifer) as influenced by extraction conditions. Food Chemistry, 152, 276-284.

Strauss, G., \& Gibson, S.M. (2004). Plant phenolics as crosslinkers of gelatin gels and gelatin-based coacervates for use as food ingredients. Food Hydrocolloids, 18, 81-89.

Tavassoli-Kafrani, E., Goli, S.A.H., \& Fathi, M. (2017). Fabrication and characterization of electrospun gelatin nanofibers crosslinked with oxidized phenolic compounds. International Journal of Biological
Macromolecules, 103, 1062-1068.

Temdee, W., \& Benjakul, S. (2014). Effect of oxidized kiam wood and cashew bark extracts on gel properties of gelatin from cuttlefish skins. Food Bioscience, 7, 95-104.

Temdee, W., \& Benjakul, S. (2015). Effect of phenolic compounds and bark/wood extracts oxidised by laccase on properties of cuttlefish (Sepia pharaonis) skin gelatin gel. International Food Research Journal, 22, 246-253.

Theerawitayaart, W., Prodpran, T., Benjakul, S., Nilsuwan, K., \& de la Caba, K. (2021). Storage stability of fish gelatin films by molecular modification or direct incorporation of oxidized linoleic acid: Comparative studies. Food Hydrocolloids, 113, 106481.

Vate, N.K., \& Benjakul, S. (2016). Effect of the mixtures of squid ink tyrosinase and tannic acid on properties of sardine surimi gel. Journal of Food Science and Technology, 53, 411-420.

Zhao, Y., \& Sun, Z. (2017). Effects of gelatin-polyphenol and gelatin-genipin cross-linking on the structure of gelatin hydrogels. International Journal of Food Properties, 20, S2822-S2832. 